\title{
Jellyfish outbreaks in coastal city beaches from a management perspective
}

\author{
G. Rodríguez, G. Clarindo \& L. McKnight \\ Applied Marine Physics and Remote Sensing Group, Departamento \\ de Física, Universidad de Las Palmas de Gran Canaria, Spain
}

\begin{abstract}
Jellyfish outbreaks are a worldwide natural phenomena, which may offer opportunities but also lead to difficulties to humans. In particular, they are viewed as natural hazards in coastal areas, especially in urban beaches with a high density of users, where they may present a significant risk. This paper examines the role of jellyfish outbreaks into coastal urban beaches in terms of the actions to be taken to combat these events and to develop support policies, which allow preserving the environment while satisfying social needs. The case study of Las Canteras beach (Canary Islands) is described as a representative example.
\end{abstract} Keywords: jellyfish outbreaks, city beaches, beach management.

\section{Introduction}

The presence of jellyfish in coastal areas is a natural phenomenon that may constitute a more or less serious hazard for people, their goods and interests. In general, the risk associated to the presence of a few of these organisms is almost negligible. However, the landscape hazard changes drastically in the presence of some jellyfish species swarms. Their massive arrival to the coast, usually referred to as jellyfish outbreaks or blooms, may have important implications from different points of view. In particular, invasions of beaches by harmful jellyfish species during good weather and holiday periods, inviting people to swim and practice water sports like diving or surfing, could have a significant negative effect. As a consequence, the occurrence of jellyfish swarms in coastal areas, especially on beaches with a high density of users, represents a problem that must be properly managed to support recreational needs and tourism industry demands, as well as socioeconomic activities related to the use of the beaches, without jeopardizing environmental values. 
The massive appearance of jellyfish in a given area is commonly referred to both as jellyfish bloom or outbreak. In fact, the occurrence of a swarm can be due to a rapid population growth, motivated by the existence of favourable conditions for reproduction, or to the sporadic appearance of a large number of individuals in a given place, due to the redistribution or dispersion of a stable population, as a consequence of physical, chemical, or behavioural factors [1]. In this paper, the term bloom will be reserved to refer to the first situation while jellyfish outbreak will be used in the latter context, which forms the subject of this study.

This paper addresses various issues related to the occurrence of jellyfish outbreaks in coastal waters and their management, with special emphasis on their appearance on urban beaches. Furthermore, the occurrence of jellyfish outbreaks and the adopted management strategies in Las Canteras beach is used as a representative case of study, discussing the actions undertaken during previous documented events, as well as the needs for improving management approaches to eliminate or alleviate the impact of this particular natural hazard.

The rest of the paper is structured as follows. The next section presents a brief overview of jellyfish outbreaks possible positive and negative effects on humans. After that, the social and economic role of urban beaches are highlighted. Joint consideration of jellyfish outbreaks impact and the socio-economic interest of beaches betray the need to develop suitable management strategies to tackle problems concerning the occurrence of jellyfish outbreaks on urban beaches. Then, different aspects to be considered for improving beach management in this context are described, including the supply of adequate information to beachgoers, assessment of public perception of the phenomenon, mitigating measures, as well as the need for scientific and technical improvements for jellyfish outbreaks monitoring and prediction. Following this, the occurrence of such natural events and the actions undertaken to avoid or alleviate associated risks in Las Canteras beach (Gran Canaria Island, Canary Islands), an urban beach with a high density of users, are examined as an illustrative example of beach management in this context.

\section{Jellyfish benefits and constraints}

Jellyfish are animals belonging to the phylum Cnidaria that spend all or part of their life suspended or drifting in water and have some self-propulsion capacity, by squirting water on the surrounding fluid. However, this capacity is almost negligible in comparison with the drag exerted on these organisms by wind and currents, which results in large-scale advection of jellyfish colonies. Once these have reached the nearshore zone, they are transported by waves towards the shore and become stranded on the beach.

A literature review evidences the existence of two opposing images of jellyfish as organisms inducing both problems and benefits to society [2]. A brief and comprehensive summary on this controversial topic has recently been published by Malej et al. [3].

On the one hand, it is well recognized that jellyfish play an important role in the marine food chain. They feed mainly on a large variety of zooplankton and 
serve as food for various fish species and sea turtles. To capture food and as a defence against predators, jellyfish use stinging cells. Furthermore, jellyfish have had a transcendental impact in pharmacology and medicine, triggering great advances, such as possible applications of jellyfish toxins as anti-cancer compounds [4], treatment of high blood pressure [5], or anti-oxidant supplements in nutrition [6].

Some jellyfish species are considered as a delicacy food and have been fished for a long time in Asian countries. Paradoxically, catches declined sharply around the seventies due to overfishing. However, scientific advances have improved the situation. For this and other reasons, such as their use for aquarium exhibiting and scientific purposes [7], jellyfish aquaculture production has increased during the last decades.

A radically different reading of the role of the jellyfish is found when examining the most tangible effects related to the direct interaction of these organisms with man, their goods and interests, some of which are briefly discussed below.

The negative economic impact of jellyfish outbreaks on fisheries and the fishing industry may be either direct or indirect. In the first case, the impact is generally due to the direct interference with fishing activities, such as fishing nets clog, and by endangering fishermen's health. Indirect implications are mainly related with their effects on fish populations [8]. Specifically, jellyfish can be a voracious competitor for zooplankton, thus reducing availability of food for fish, and they can also feed on fish eggs and larvae. Accordingly, it is plausible that effects of jellyfish outbreaks on the fishing industry extend to other industries, such as tourism, by limiting fish supply to hotels and restaurants [9]. Moreover, different jellyfish species invasions have been associated with large mortality events of fish in aquaculture farms. Hypoxia, mechanical damage and toxicity via nematocysts discharge, has been indicated as effects of jellyfish on aquaculture products [10].

Desalination plants, as well as thermal and nuclear power plants located on the coast require the supply of large quantities of seawater to operate. Then, seawater intakes are at the risk of jellyfish swarms ingress causing their clogging and blocking the pumping of seawater needed [11]. This is also true for cooling systems of vessels [12].

In addition, a man can be stung if he comes into contact with the tentacles of some jellyfish species. Although it is known that most jellyfish species are innocuous to humans and that jellyfish do not attack men, some species are harmful and can cause mild, severe, and even fatal injuries when humans come into fortuitous contact with their tentacles. This threat for human health is by far the main reason why jellyfish are known and the origin of their negative public perception.

\section{The socio-economic role of beaches}

From the physical point of view, beaches can be considered as dynamical systems with a very complex behaviour, changing and adapting their physiography to the 
action of hydrodynamic coastal processes operating over different space and time scales, to maintain their fragile equilibrium, which is extremely susceptible to anthropogenic actions.

Beaches can be classified according to many different aspects. Thus, for instance, in relation to their physical characteristics, they may be grouped into stable and unstable; dissipative, reflective, and intermediate; and so on. In terms of their geographical location, beaches can be classified as resort, urban, village, rural and remote [13]. Urban beaches are those located within or adjacent to an urban area, which provide well-established public services to large populations. Furthermore, in general, beaches serve as the most important recreation amenity for the urban residents, and also for tourists. In the specific case of a beach located in a coastal zone and completely integrated within a big city we will refer to it as a city beach. Additionally, beaches can also be classified in terms of user density as heavy, medium and dense [13]. Furthermore, according to their usage, these could roughly be classified as bathing and relaxing areas, aquatic sport zones, and beaches of combined use.

Thus, from a more general point of view, urban or city beaches should be considered as complex systems exhibiting a substantial variety of functions, such as coastal defence, acting as a buffer zone to dissipate wave energy, providing recreation opportunities (swimming, surfing, fishing, and so on), and supporting special ecological systems, among others [14]. Furthermore, beaches stimulate the development of numerous social and commercial activities in their surroundings, such as graphically illustrated in Figure 1. Consequently, beaches are a frequent source of different types of conflicts, including physical, ecological, and socioeconomic aspects. In this context, beach management should balance usage and development of beach resources, preserving the environment and satisfying social needs.

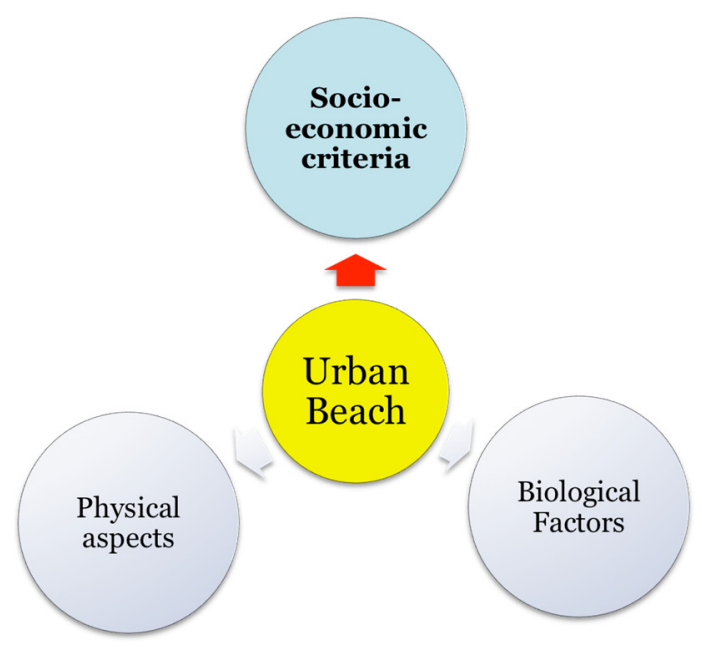

Figure 1: Schematic illustration of the main factors commonly involved in urban beach management. 
Focusing on socioeconomic aspects, beach management should take into account a large variety of factors to provide social needs and preserve the environment. These include, among others, accessibility conditions for beach users, commercial and cultural activities development, landscape and environmental conservation, as well as to undertake actions to provide optimal safety and health conditions, such as depicted in Figure 2.

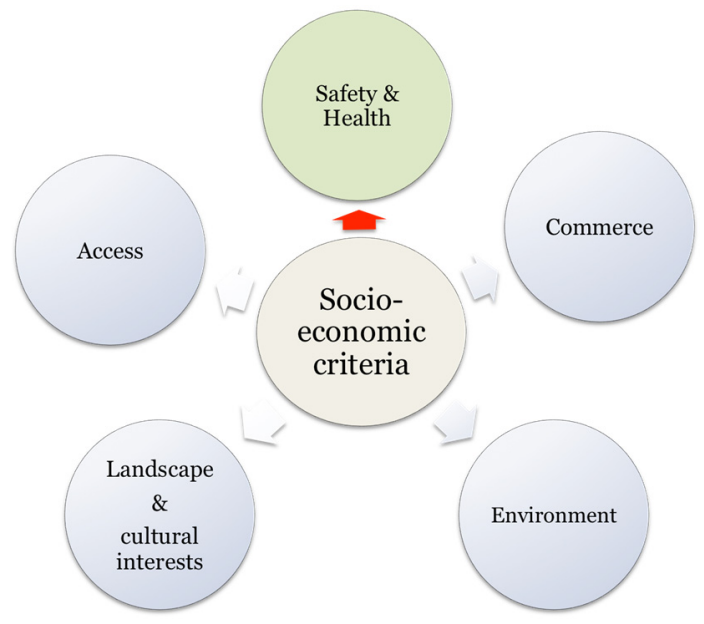

Figure 2: Schematic illustration of the main socioeconomic aspects concerning urban beach management, highlighting the importance of safety and health factors.

\section{Management of jellyfish outbreaks on city beaches}

In a nutshell, a city beach represents a usually small area of great socio-economic value for the residents, which must be properly managed to preserve or improve its quality, taking into account a wide variety of factors, including physical, ecological, health and safety aspects, as well as legal and socio-economic issues, among others. In particular, as a natural phenomenon with a certain probability of occurrence and notable consequences on the human health and safety, goods, and interests, jellyfish outbreaks have to be considered as natural hazards that must be properly managed to minimize associated risk.

Beach safety has been defined as "the limitation or mitigation of risk and hazards that expose the public to danger or harm while in a beach environment" [15]. Naturally, this definition makes evident the need to adopt strategies to minimize the impact of possible jellyfish outbreaks occurrence, as a clear factor to be considered to provide beach safety.

Coastal zones, in general, and beaches in particular, can be affected by many different kinds of natural or human-induced hazards, endangering human health and safety. In this context, beach management plans generally focus on natural hazards of meteo-hydrological nature (hurricanes, wind storms, storm surges, 
extreme waves, rip currents, etc.) or in anthropogenic hazards related to water quality (domestic and industrial sewage effluents, brine disposals, oil spills, etc.). However, the increasing use of beaches for recreational activities has enhanced human interaction with marine organisms, leading to a rise in contacts with dangerous organisms [16-18]. This fact calls for a broader perspective in the development of beach management plans. Some recent interesting works highlight the importance of jellyfish outbreaks in coastal and beach management $[13,19$, 20].

\subsection{Managing strategies}

Numerous strategies have been tried for managing beaches in case of jellyfish outbreaks [21]. However, these can be roughly grouped into five main subcategories:

Supply of relevant information to beachgoers on what to do in case of jellyfish encounters in the water and dead jellyfish on the sand, how to avoid stings in case bathing is allowed; how to act in the event of stings.

Assessment of public perception, to know how users perceive this natural hazard and assess this information for taking decisions and developing management plans.

First-aid and medical services provision on the beach, as well as in nearby medical centres when required.

Use of mitigating measures when jellyfish invasions occur or have been predicted. These can include action to prevent the arrival to the bathing area, such as the use of anti-jellyfish nets or special vessels to remove it from the water, or to adopt measures to remove jellyfish from shallow waters or sand, such as nets operated by hand or devices for ploughing the sand (see Figure 3).

Implement monitoring and prediction programs. Technological advances must be incorporated to the monitoring procedures, in addition to the conventional ones, frequently based on lifeguards observations or services. The most conventional procedure to acquire information on jellyfish abundance consists in sampling through trawled nets from vessels. However, this approach has several drawbacks. Remote sensing can help to alleviate these limitations but do not allow for obtaining data of abundance in the water column. Hydro-acoustic methods are considered among the more adequate to obtain valuable information on abundance [21]. Prediction procedures need long time series of observations, including jellyfish detection, as well as oceanographic and meteorological conditions giving rise to swarms [22].

\section{Case study: jellyfish outbreaks in Las Canteras beach}

Las Canteras beach is a $3 \mathrm{~km}$ length fine-grain yellow sand city beach located in the north side of the Gran Canaria Island, providing recreational opportunities to the citizens of Las Palmas de Gran Canaria, the largest and most heavily populated city in the Canary Islands (about 400,000 inhabitants). It exhibits the particular geomorphological characteristic of being a semi-enclosed beach by a natural rocky reef (see Figure 4). 


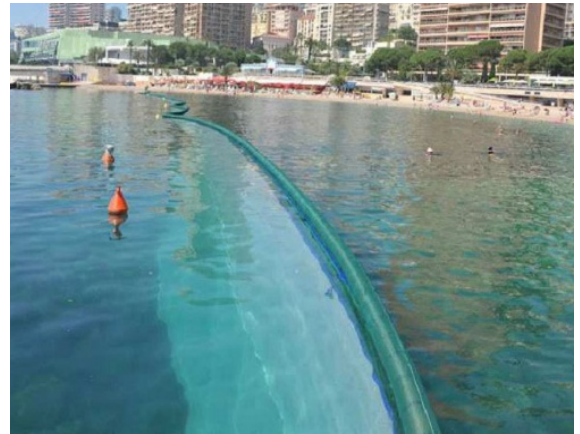

(a)

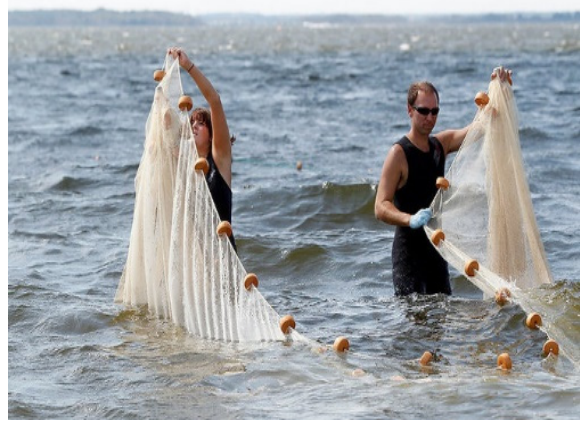

(c)

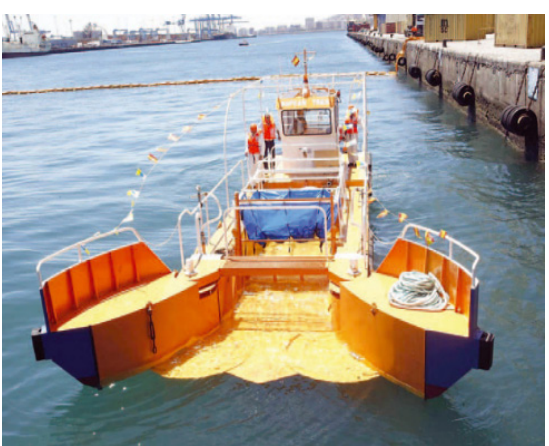

(b)

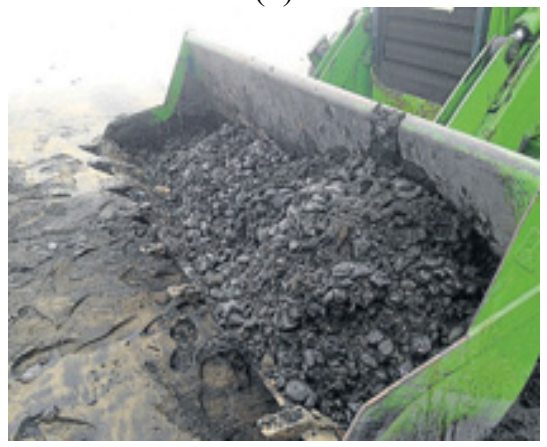

(d)

Figure 3: Measurements for the prevention of jellyfish arrival on beaches: (a) anti-jellyfish nets, (b) adapted vessels, (c) recovery in shallow waters with nets, and (d) tractor to remove it from sand.

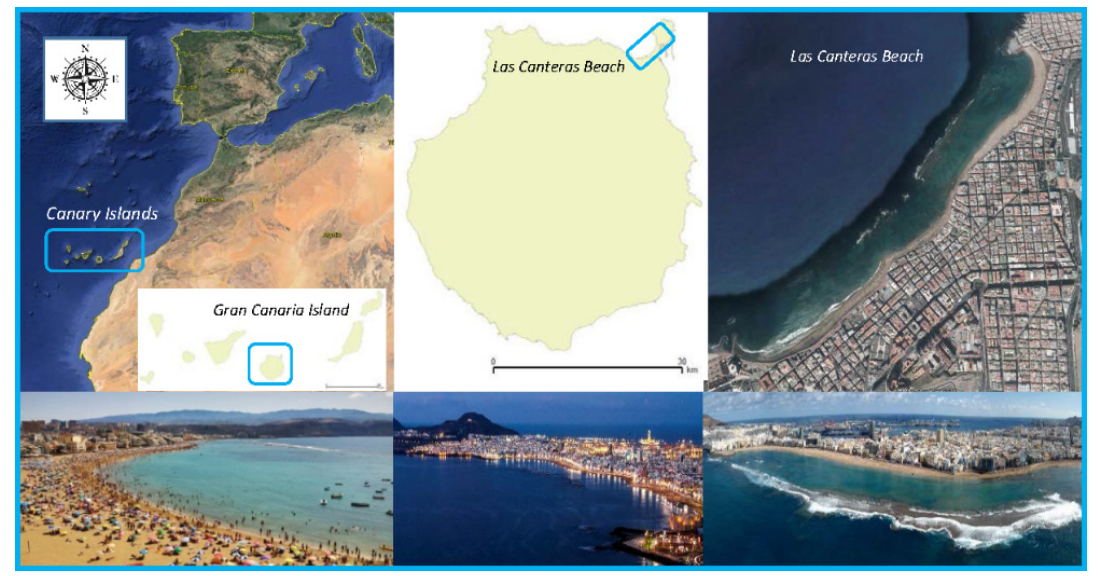

Figure 4: Composite of images showing Las Canteras location (upper panels) and different views revealing their main role as a bathing beach for a densely populated city, as well as the offshore rocky reef. 
According to the information available, the most common outbreaks occurring at this beach, as well as on other beaches in the islands, are generated by the presence of two species. The largest frequency corresponds to outbreaks of Pelagica noctiluca. Far less common is the occurrence of Physalia physalis, commonly known as Portuguese man-of-war. P. noctiluca belongs to phylum Cnidaria, group Scyphozoa, or true jellyfish. It is well known for its painful sting, which is very unpleasant due to the numerous venomous nematocysts covering its body. Figure 5(a) shows individuals of this species stranded on Las Canteras beach. $P$. physalis belongs to the phylum Cnidaria, group Hydrozoa, but is commonly and misleadingly included in the jellyfish group (Scyphozoa). It can be easily recognized by its prominent purple-blue float that supports the stinging cells on the tentacles hanging below. Stings by the various Physalia species are the most common marine stings known at present and their nematocysts remain active even when beached. The Atlantic species (P. physalis) is the most dangerous one and has been responsible for some severe stings (see [17] and references therein). A specimen stranded on Las Canteras beach is shown in Figure 5(b).

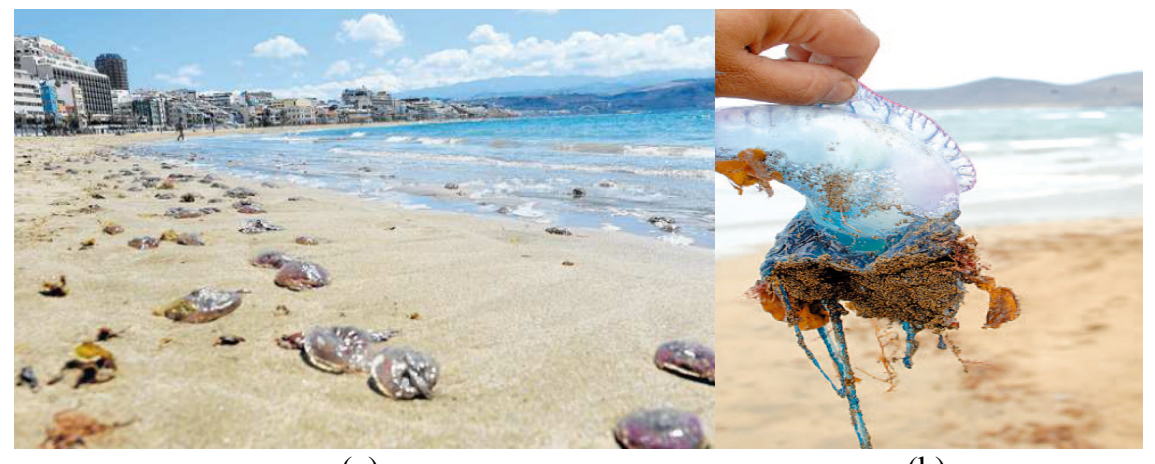

(a)

(b)

Figure 5: $\quad$ Pelagia noctiluca outbreak (a) and specimen of P. physalis (b) in Las Canteras beach (Source: Canarias7).

The monthly number of stings reported by the Red Cross lifeguards from 2009 to 2014 are shown in Figure 6. The global monthly average over the five years (upper panel) seems to reveal a clear annual cycle with a maximum during summer months progressively decreasing towards a minimum in winter. However, the evolution of monthly values makes evident a large variability both intra-annual and inter-annual in this variable.

It is important to emphasize that a large portion of the existing information on outbreaks at a given beach has been obtained in terms of the number of patients treated by the emergency services located at the beach or in nearby hospitals. Since most affected people treat themselves, it is difficult to determine the total annual number of cases. Furthermore, use of beaches is clearly higher during summer and warnings against jellyfish outbreaks reduce drastically the number of beach users and, as a consequence, the stings. Therefore, although this type of information is 

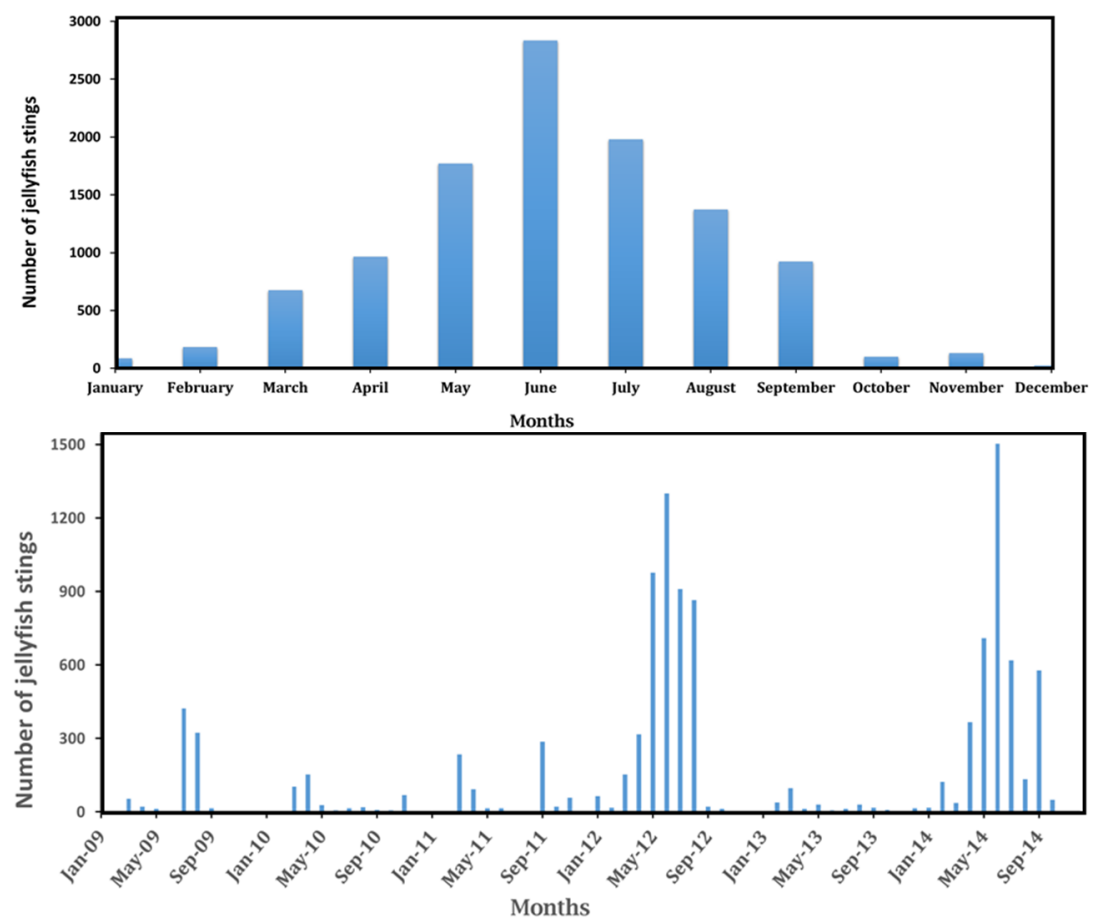

Figure 6: Monthly evolution of jellyfish stings in the period 2009-2014 (upper) and mean year pattern for the same period (lower).

of great value, it should be used with caution for assessing time patterns of jellyfish abundance.

In terms of public perception of these episodic but recurrent events, an interview conducted with beachgoers by the local newspaper Canarias7, during an outbreak episode, with the general question: "Should authorities take measures against jellyfish invasion?" The main result of the survey was a clear parity between those favouring actions (58\%) and those opposing (40\%). 2\% of those surveyed did not know or failed to respond.

Nevertheless, due to the importance of the beach use for residents and tourists, especially during good weather and summer holiday periods, inviting to swim and practice water sports like diving or surfing when outbreaks seem to be more frequent and massive, local authorities have undertaken various actions to avoid or alleviate associated risks. Thus, relevant information about jellyfish species commonly observed and what to do in case of jellyfish presence or sting is provided to beachgoers by means of posters located at easily visible locations, such as beach accesses (see Figure 7(a)). Furthermore, Red Cross lifeguards undertake surveillance activities at different locations along the beach indicating the presence of jellyfish, if applicable, by planting a special flag (see Figure 7(b)). In addition, in such a case, information is provided by the public address system installed along the beach promenade. 


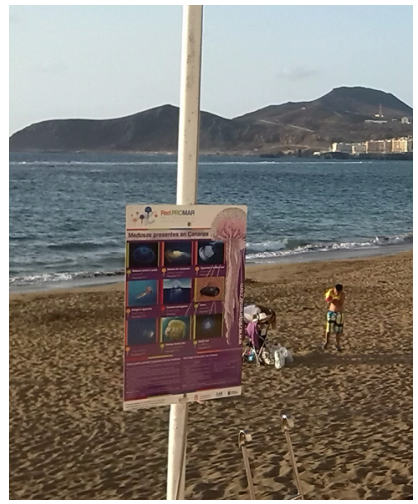

(a)

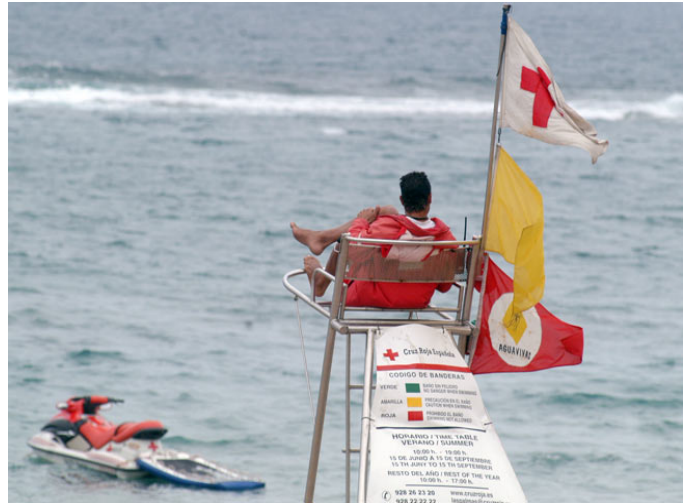

(b)

Figure 7: Poster located in a beach access with information on jellyfish and on how to act in case of sting (a). Red Cross lifeguard during surveillance activities with flag indicating the presence of jellyfish (b).

In case of invasion, the daily cleaning services, which usually operate during night, adds extra turns to remove stranded jellyfish (see Figure 8(b)). Moreover, in case of swarm arrivals during summer season, adapted vessels to remove oil spills in shallow waters have been used for recovering jellyfish from water (Figure $8(\mathrm{a})$ ).

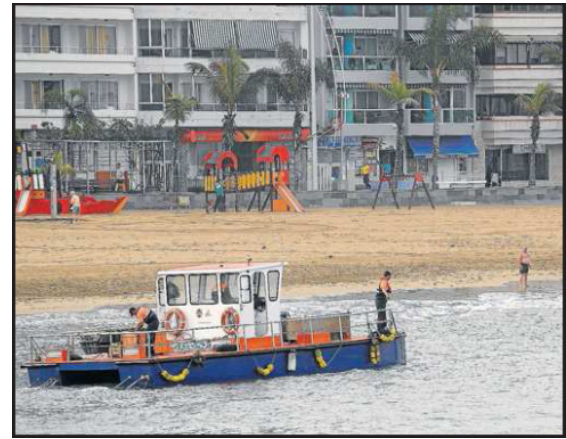

(a)

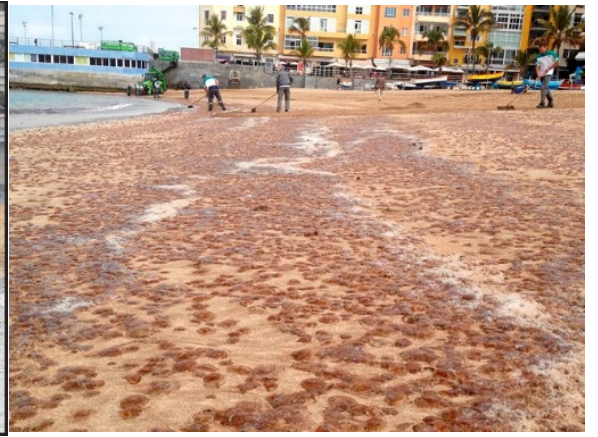

(b)

Figure 8: Catamaran adapted for oil spills cleaning operations removing jellyfish (a) and personnel of the beach cleaning service (b) operating during a jellyfish outbreak in Las Canteras beach (Source: Canarias7).

Currently, monitoring activity is mainly based on observations made by Red Cross lifesavers. Regional Environment Council and General Direction of Public Health of the Canary Government have implemented RedPromar, a monitoring and alert network of voluntary observers of the marine environment. Thus, any 
person who sights jellyfish can report it by accessing the website www.redpromar.com, from different multimedia devices.

In the light of the previous comments, it may be said that informative and mitigating aspects are covered by the existing beach management plan. However, it is clearly not enough. Monitoring strategies should be implemented and predictive models developed to help take judicious and quick decisions, as well as to optimise efficiency of the actions to be undertaken, minimizing the number of stings, which in June 2014 was the highest recorded up to now.

\section{Acknowledgements}

The authors would like to thank the Beach Department of Las Palmas de Gran Canaria Council and Red Cross in Las Palmas for kindly providing data used in this study.

\section{References}

[1] Graham, W.M., Pages, F. and Hamner, W.M., 2001. A physical context for gelatinous zooplankton aggregations: a review. Hydrobiologia, 451, pp. 199-212.

[2] Duarte, C.M., Pitt, K.A. and Lucas, C.H., 2014. Introduction: Understanding Jellyfish Blooms. In Jellyfish Blooms, K.A. Pitt and C.H. Lucas (eds.), Springer.

[3] Malej, A., Kogovsek, T. and Uye, S.I., 2014. Medusae - Pest or resource for humans? Biologia Marina Mediterranea, 21(1), pp. 2-9.

[4] Balamurugan, E., Bandugula, R. and Venugopal, M., (2010). Antitumor and antioxidant role of Chrysaora quinquecirrha (sea nettle) nematocyst venom peptide against ehrlich ascites carcinoma in Swiss Albino mice. Molecular and Cellular Biochemistry, 338, pp. 69-76.

[5] Zhuang, Y., Sun, L., Zhang, Y. and Liu, G., 2012. Antihypertensive Effect of Long-Term Oral Administration of Jellyfish (Rhopilema esculentum) Collagen Peptides on Renovascular Hypertension. Marine Drugs, 10(2), pp. 417-426.

[6] Yu, H., Liu, X., Xing, R., Liu, S., Guo, Z., Wang, P., Li, C. and Li, P., 2006. In vitro determination of antioxidant activity of proteins from jellyfish Rhopilema esculentum. Food Chemistry, 95, pp. 123-130.

[7] Purcell, J.E., Baxter, E.J. and Fuentes, V. 2013. Jellyfish as products and problems for aquaculture. In: Allan G. and Burnell G. (eds), Advances in aquaculture hatchery technology. Woodhead Publishing.

[8] Palmieria, M.G., Barausse, A., Luisetti, T. and Turner, K., 2014. Jellyfish blooms in the Northern Adriatic Sea: Fishermen's perceptions and economic impacts on fisheries. Fisheries Research, 155, pp. 51-58.

[9] Nastav, B., Malej, M., Malej Jr., A. and Malej, A., 2013. Is it possible to determine the economic impact of jellyfish outbreaks on fisheries? A Case Study - Slovenia. Mediterranean Marine Science, 14(1), pp. 214-223. 
[10] Baxter, E.J., Sturt, M.M., Ruane, N.M., Doyle, T.K., McAllen, R., Harman, L. and Rodger, H.D., 2011. Gill damage to Atlantic salmon, Salmo salar, caused by the common jellyfish, Aurelia aurita, under experimental challenge. PLoS ONE, 6(4), e18529.

[11] Abdul Azis, P.K., Al-Tisan, I., Al-Daili, M., Green, T.N., Dalvi, A.G.I. and Javeed, M.A., 2000. Effects of environment on source water for desalination plants on the eastern coast of Saudi Arabia. Desalination, 132(1-3), pp. 2940.

[12] Siokou-Frangou, I., Sarantakos, K. and Christou, E.D., 2006. First record of the scyphomedusa Rhopilema nomadica Galil, 1990 (Cnidaria: Scyphozoa: Rhizostomeae) in Greece. Aquatic Invasions, 1(3), pp. 194-195.

[13] Williams, A. and Micallef, A., 2009. Beach Management: Principles and Practice. B. Routledge.

[14] Carter, R.W.G., 1988. Coastal Environments - An Introduction to the Physical, Ecological and Cultural Systems of Coastlines. Academic Press Limited, London.

[15] De Nardi, M. and Wilks, J., 2008. Beach safety. In Encyclopaedia of tourism and recreation in marine environments, ed. M. Luck, 57. London: Routledge.

[16] World Health Organization 2012, International Travel and Health.

[17] World Health Organization 2003, Guidelines for safe recreational waters; Volume 1: Coastal and fresh waters.

[18] Finkl, C.W. and Makowski, C., 2013. The Southeast Florida Coastal Zone (SFCZ): A Cascade of Natural, Biological, and Human-Induced Hazards. In Coastal Hazards, Ed. Finkl, C.W., Springer.

[19] Gershwin, L.A., De Nardi, M., Winkel, K.D. and Fenner, P.J., 2010. Marine Stingers: Review of an Under-Recognized Global Coastal Management Issue. Coastal Management, 38, pp. 22-41.

[20] Baumann, S. and Schernewski, G., 2012. Occurrence and public perception of jellyfish along the German Baltic Coastline. Journal of Coastal Conservation, 16(4), pp. 555-566.

[21] Gibbons, M.J., Richardson, A.J., 2013. Beyond the jellyfish joyride and global oscillations: advancing jellyfish research. Journal of Plankton Research, 35, pp. 929-938.

[22] Gershwin, L.A., Condie, S.A., Mansbridge, J.V. and Richardson, A.J., 2014. Dangerous jellyfish blooms are predictable. J. Roy. Soc. Interface, 11(96). 